\title{
Gestão de Conflitos em TI: A Importância da Inteligência Emocional
}

\author{
Raphael de Paiva Gonçalves ${ }^{1}$ e Henri Cardim ${ }^{2}$ \\ ${ }^{1}$ Instituto Federal de Educação, Ciência e Tecnologia de São Paulo, São João da Boa Vista, Brasil \\ ${ }^{2}$ HFC Consultoria e Associados, Marília, Brasil
}

\begin{abstract}
Conflitos são inerentes às organizações e podem ter consequências funcionais e disfuncionais aos objetivos organizacionais. Conflitos podem ser relacionados à tarefa, ao processo ou ao relacionamento, sendo este último, na maioria das vezes disfuncional ${ }^{6}$. A resolução destes conflitos pode ser realizada de várias maneiras, tendo a gestão de conflitos como mecanismo importante neste processo. A gestão de conflitos tem com princípio fundamental a negociação, que em todas as suas etapas, exige aptidões de inteligência emocional. Neste sentido, a inteligência emocional tem provocado uma ruptura em relação à demanda de competências profissionais, às quais são fortemente ligadas à aptidões de Inteligência Racional. Ambos os tipos de inteligência não devem ser consideradas de maneira excludente, mas sob a ótica da unificação de suas utilidades em prol do desenvolvimento de um profissional mais íntegro. Tal fundamentação torna-se de grande importância em relação ao profissional de TI, em especial à gestores de TI, tendo em vista a essencialidade da TI nas organizações modernas e seu potencial estratégico organizacional. Nesta perspectiva, este trabalho visa apresentar uma reflexão, realizada a partir de uma revisão bibliográfica, sobre a relação de importância da aquisição de competências e aptidões emocionais por profissionais de TI para o êxito na gestão de conflitos profissionais nas organizações.
\end{abstract}

Index Terms-Tecnologia da Informação, Gestão de Conflitos, Inteligência Emocional.

\section{INTRODUÇÃO}

$\mathbf{C}$ ONFLITO pode ser definido como a divergência entre duas ou mais opiniões, teorias, hipóteses ou concepções. Neste sentido, os conflitos são intrínsecos à relação interpessoal na sociedade, visto que nem sempre as pessoas e grupos compartilham de propósitos afins.

Nesta perspectiva, conflitos são praticamente inevitáveis e podem ocorrer no âmbito familiar, social e profissional ${ }^{1}$. No caso do ambiente profissional, organizações podem ser acometidas de conflitos entre gestores, gestor e subordinado, entre subordinados, e ainda entre estes e os clientes, fornecedores ou outros possíveis atores que se relacionem com a organização.

Visto que uma organização é a junção do empenho individual para a conquista de objetivos coletivos, os conflitos, se não gestionados e resolvidos de maneira correta, podem ser negativos e ocasionar a ruptura da unidade organizacional e logo, o impedimento do êxito nos objetivos organizacionais ${ }^{2}$.

A partir disto, a gestão de conflitos tem se tornado cada vez mais importante dentro das organizações, levando em consideração a complexidade da identificação e administração de conflitos, a busca de suas possíveis soluções e à satisfação das partes envolvidas ${ }^{1}$.

$\mathrm{Na}$ área de Tecnologia da Informação (TI), a qual hoje com a crescente e contínua transformação tecnológica dentro das empresas, é um setor fundamental, senão essencial, a gestão de conflitos faz-se ainda mais importante, visto que, na maioria das situações, devido ao processo de transição para a essencialidade da TI nas organizações, tais setores enfrentam diversas dificuldades e desafios relacionados, principalmente à visão da TI como custo e não como investimento, o que ocasiona, dentre outras, na insuficiente quantidade profissionais na equipe do setor e por conseguinte pressões em relação à prazos, demandas no fim de semana, trabalho imprevisível, estresse, boundary-spanning e diversos outros tipos de situações conflituosas ${ }^{3}$.

Profissionais de TI são, geralmente, pessoas com altas competências racionais e de formulação e resolução de questões lógicas e exatas, os quais são requisitos fundamentais para interação com computadores de forma complexa. Porém, tal competência intelectual não garante a mesma habilidade em questões interpessoais e relacionadas à inteligência emocional $^{4}$.

A inteligência emocional pode ser definida a partir de aptidões intrapessoais e interpessoais, como: Conhecer as próprias emoções (Autoconsciência), lidar com emoções (Autocontrole), motivar-se (Automotivação), reconhecer as emoções nos outros(Empatia) e lidar com relacionamentos (Gestão de Relacionamentos) ${ }^{4}$. Aptidões às quais são fundamentais para trabalhar em equipe e principalmente, gerenciar conflitos.

Nesta concepção, este trabalho visa apresentar uma reflexão, realizada a partir de uma revisão bibliográfica, sobre a relação de importância da aquisição de competências e aptidões emocionais por profissionais de TI para o êxito na gestão de conflitos profissionais nas organizações.

Junho, 2018

\section{A. Origens do Conflito: Princípios e Concepções}

Nesta sessão serão abordadas diversas definições e conceituações de conflito descritas pela literatura, a fim de iniciar a elucidação do tema e posteriormente relacionar quais são as consequências da ocorrência destes e possiveis delineamentos sobre a resolução e gerenciamento de conflitos.

\section{1) Definições de Conflito}

Inicialmente, cabe ressaltar que a análise e gestão de conflitos nas organizações é comumente realizada na literatura pela área pesquisa em administração de empresas, mais especificamente em relação a comportamento organizacional. 
Em 1974, foram definidas três competências básicas para um administrador: técnicas, humanas e conceituais ${ }^{5}$. As competências técnicas podem ser difinidas como a habilidade de aplicar o conhecimento em situações específicas, as competências humanas são habilidades de trabalhar com outras pessoas, compreendo-as, motivando-as e gerenciando possiveis conflitos individuais e coletivos e, por fim, as competências conceituais são capacidades de análise, diagnóstico e tomada de decisão em situações complexas ${ }^{6}$.

Nesta perspectiva, a partir do início da década de 90 emerge a importância da análise da relação de interferência do comportamento humano na eficácia dos resultados da organização, os quais anteriormente eram apenas fundamentados com base nas competências técnicas da gestão desta organização ${ }^{6}$.

Uma organização pode ser definida como uma unificação social, composta de duas ou mais pessoas, organizada funcional e hierarquicamente, a fim de trabalhar em prol de um ou mais objetivos.

Sendo assim, o comportamento organizacional é definido como "um campo de estudos que investiga o impacto que indivíduos, grupos e a estrutura têm sobre o comportamento dentro das organizações, com o propósito de utilizar este conhecimento para melhorar a eficácia organizacional" (ROBBINS; JUDGE, 2014; pag.3). Neste sentido, o comportamento organizacional é a análise do comportamento das pessoas nas organizações e como este afeta o desempenho e a realização dos objetivos organizacionais.

A divergência entre esses comportamentos individuais e/ou coletivos leva à geração de conflitos entre os respectivos divergentes e neste sentido, um conflito pode ser definido como "processo que tem início quando uma das partes percebe que a outra parte afeta, ou pode afetar, negativamente alguma coisa que a primeira considera importante." (ROBBINS; JUDGE, 2014; pag.299). Ferreira (2009) define conflito como "[...] Oposição entre duas ou mais partes; Desavença entre pessoas, grupos; Divergência, discordância de ideias, de opiniões.". Houaiss (2009), traz definições frente a multivariados contextos; primeiramente, define conflito como: "profunda falta de entendimento entre duas ou mais partes; discussão acalourada, altercação; ato, estado ou efeito de divergirem acentuadamente ou de se oporem duas ou mais coisas.", no contexto administrativo, define como: "contestação recíproca entre autoridades pelo mesmo direito, competência ou atribuição.", na Psicologia: "ocorrência concomitante de exigências, impulsos ou tendências antagônicos e mutuamente excludentes e o estado daí decorrente.", em relação ao termo jurídico: "[...] contestação recíproca entre indivíduos ou nações que aspiram a mesma vantagem ou disputam direitos antagônicos.".

A partir das definições de conflito supracitadas, entendese conflito como a divergência entre duas ou mais opiniões, teorias, hipóteses ou concepções. Nesta definição mais conjectural pode-se depreender que conflitos são inerentes à vida organizacional e como organizações são pessoas trabalhando por objetivos, pode-se relacionar paralela, associativa e consequentemente que conflitos são inerentes à vida interpessoal.

\section{2) Consequências Organizacionais dos Conflitos}

As consequências organizacionais dos conflitos podem ser muitas e na maioria das vezes a visão estereotipada é que conflitos geram consequências negativas, o que não deve ser visto como um padrão.

A consequência de um conflito pode ser alterada dependendo da forma como ele é observado, pois isto altera drásticamente a maneira como ele será gerenciado.

Robbins e Judge (2014) afirmam que há duas visões de conflito: A tradicional e a interacionista. $\mathrm{Na}$ visão tradicionalista, conflitos são sempre negativos e prejudiciais, desfavorecendo o desempenho organizacional, sendo agravado pela sua forma de gerenciamento, na maioria das vezes irracional, violenta e disruptiva.

$\mathrm{Na}$ visão interacionista, o conflito, dependendo do seu contexto, pode trazer benefícios à organização, tirar grupos da zona de conforto, aumentar a produtividade, a capacidade de mudança e inovação ${ }^{6}$. Neste entendimento, a visão interacionista categoriza os conflitos em: funcionais e disfuncionais, considerando como base para esta divisão a consequência do conflito para a organização.

Os conflitos funcionais corroboram com os objetivos da organização, melhoram seu desempenho, quebram a zona de conforto quanto à produção e portanto podem ser considerados conflitos construtivos, positivos e benignos.

Os conflitos disfuncionais ou destrutivos prejudicam o desempenho da organização, rompem a unidade social e assim sendo são tidos como negativos, desfavoráveis e contraproducentes.

A partir disto, para categorizar um conflito em funcional ou disfuncional é necessário compreender à qual contexto organizacional àquele conflito esta relacionado, isto é, se ele se relaciona à tarefa, ao relacionamento ou ao processo ${ }^{6}$.

JEHN (1997), afirma que conflitos de tarefa estão relacionados ao conteúdo e objetivos do trabalho. Conflitos de relacionamento tem foco no relacionamento interpessoal. Os conflitos de processo estão relacionados a como o trabalho é realizado. Então, respectivamente, podemos observar conflitos em relação a o que fazer, com quem fazer e como fazer.

Robbins e Judge (2014) afirmam que há estudos que demonstram que conflitos de relacionamento são, na maioria das vezes, disfuncionais. Tal categorização se dá pois conflitos de relacionamento acentuam atritos e confrontos, colocando foco nas críticas de personalidade, atitudes e de estilo interpessoal ${ }^{10}$. Este processo contribui para o rompimento da empatia e dificultam o entendimento mútuo, podendo levar à diminuição da confiança, nível de cooperação e aumento do nível de estresse na organização.

Em divergência, conflitos de processo em baixa quantidade e níveis baixos a moderados de conflitos de tarefa podem ser categorizados como funcionais. Nestes níveis, conflitos de processo e de tarefa levam à discussão de idéias, otimização de procedimentos, estimulam a criatividade e a inovação, promovendo aumento da produtividade e desempenho ${ }^{6}$.

A partir destas concepções, pode-se observar que conflitos, em alta intensidade, sejam de tarefa, relacionamento ou processo, tornam-se disfuncionais e são prejudiciais às organizações. Robbins e Judge (2014) afirmam ainda que, raramente, 
as pessoas envolvidas em conflitos conseguem distinguir o contexto deste, onde, conflitos de tarefa e de processos podem facilmente virar conflitos de relacionamento e vice-versa.

Assim, é indispensavél que gestores estejam sempre atentos à percepção de conflitos e tenham as competências necessárias para o gerenciamento e resolução destes, garantindo à minimização de consequências negativas e maximização de resultados positivos para a organização.

\section{3) Delineamentos sobre a Resolução e Gestão de Conflitos}

Após a percepção de indícios que criam oportunidades para o surgimento de um ou mais conflitos, cabe às partes envolvidas, principalmente aos gestores daquela organização, equipe, setor ou grupo, decidirem qual é o interesse da gestão de conflitos e relaciona-lo à abordagem de interação com a situação conflituosa, a fim de agirem de uma determinada maneira no gerenciamento desta.

Lewicki, Saunders e Barry (2014) afirmam que a literatura apresenta muitas maneiras de gerir conflitos. Tais maneiras iniciam com modelos bidimensionais parecidos e criam diferentes identificações para outros cinco fatores importantes.

O modelo bidimensional utilizado é conhecido como modelo das inquietações duais, conforme demonstrado na figura 1 .

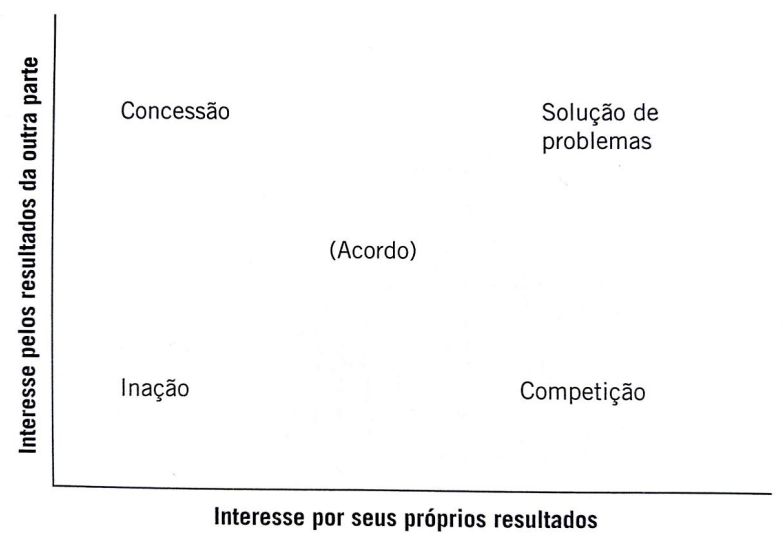

Figura 1. O modelo das inquietações duais. Fonte: LEWICKI, R. J; SAUNDERS, D. M; BARRY, B. Fundamentos de Negociação. 5.ed. New York, The McGraw Hill Education, 2014.

Inicialmente, o modelo define que os envolvidos em um conflito tem dois tipos dissociados de interesse: o interesse em seus próprios resultados e o interesse pelos resultados da parte conflitante. Ambos os interesses também são conhecidos, respectivamente, por dimensão da assertividade e dimensão da cooperação. Os quais também representam, nesta ordem, os eixos $\mathrm{x}$ e y do plano apresentado na figura 1 .

A partir disto, dependendo do nível de interesse nos resultados próprios e nos resultados da outra parte, pontos de interseção entre os eixos são traçados e expressam a forma de gerenciamento a ser utilizada naquela situação de conflito.

Fundamentado nisso, são descritos cinco pontos básicos de interseção, ou seja, cinco maneiras de interagir em uma situação de conflito, são elas: Inação, Concessão, Acordo, Competição e Solução de problemas ${ }^{11}$.
A Inação, também conhecida como aversão, tem como base baixos níves de interesse em seus próprios resultados e baixos níveis de interesse nos resultados do outro. Assim, a maneira de interação tende a ser caracterizada pela fuga do conflito, recuo, passividade. No caso do gestor do conflito, pode comportar-se de maneira a ignorar o conflito e desconsiderálo. Esta abordagem é apropriada para situações simples, para quando o confronto com a outra parte traz mais desvantagens do que as vantagens da resolução. Esta abordagem não é indicada para situações onde se tem a responsabilidade da tomada de decisão, quando as partes não estão propensas a desistir, havendo necessidade da resolução do conflito e quando uma decisão súbita é essencial.

A Concessão, também conhecida como acomodação ou consentimento, traz baixos níveis de interesse por seus próprios resultados e altos níveis de interesse pelos resultados da outra parte. Sendo assim, o conflitante ou o gestor abrem mão de suas pretenções para atender as expectativas da outra parte. Esta abordagem é apropriada para quando houver disposição para ceder algo no presente em troca de algo que a outra parte possa oferecer no futuro, para quando é indispensável preservar o relacionamento ou quando se está negociando em posição de vulnerabilidade. Esta abordagem não é indicada para quando a questão é importante, quando a outra parte possa estar errada ou não esteja agindo com ética.

O Acordo representa níveis intermediários de interesse tanto nos próprios resultados quanto nos resultados da outra parte, sendo considerado por alguns autores como uma estratégia onde as partes se esforçam para atender as demandas de ambos. Neste tipo de abordagem o gestor concilia os anseios dos conflitantes oferecendo parte dos resultados solicitados por estes. O acordo é indicado para situações onde as partes tem metas distintas e específicas, quando um entendimento não é atingido ou quando é necessário tomar uma decisão provisória para uma questão complexa. Esta abordagem não é apropriada para quando uma das partes tem mais poder de decisão.

A Competição, também conhecida como luta ou dominação, tem como base altos níves de interesse em seus próprios resultados e baixos índices de interesse nos resultados da outra parte. Esta forma de abordagem leva o conflitante ou o gestor a utilizar uma estratégia altamente focada em seus próprios anseios, ávido por defender sua posição e a persuadir e convencer a outra parte a concordar e ceder. Nesta abordagem ainda, ameaças, intimidações e coações são muito frequentes. A competição é apropriada para questões simples, que necessitam de tomada de decisão rápida, quando o plano de ação não é popular ou quando os subordinados não tem experiencia na tomada de decisões técnicas. Esta abordagem é contra indicada para situações complexas, na qual as partes tem o mesmo nível de poder ou quando os subordinados são altamente competentes.

A Solução de problemas, também denominada como colaboração ou integração, é baseada em altos índices de interesse nos resultados próprios e nos resultados da outra parte. Este tipo de abordagem tenta maximizar os ganhos de ambas as partes envolvidas e minimizar as perdas. Neste modelo, conflitantes ou gestores buscam entender a posição de cada um, a fim de promover maiores proventos e benefícios à 
todos. Esta abordagem é tida como a mais indicada para a gestão de conflitos. A solução de problemas é apropriada para conflitos com pontos complexos, quando há necessidade de síntese de opiniões para propor soluções melhores, quando o objetivo do trabalho necessita da convergência das partes envolvidas ou quando uma das partes não pode resolver o problema individualmente. Este tipo de abordagem não é indicada quando o problema é de simples resolução, quando a outra parte não tem interesse nos resultados e nem habilidades para a solução de problemas.

As abordagens citadas anteriormente compõem a essência da negociação, um princípio muito importante na gestão de conflitos. Neste sentido, a negociação é intrínseca às interações de praticamente todas as organizações. Robbins e Judge (2014; pag. 309) definem negociação como "um processo que ocorre quando duas ou mais partes decidem como alocar escassos recursos". Os autores afirmam ainda que as negociações além de gerarem impacto nos resultados organizacionais, influenciam também o relacionamento entre os negociadores, gerando consequências consoantes à maneira de abordagem de cada uma das partes no processo de negociação.

Nesta visão, Lewicki, Saunders e Barry (2014) definem dois tipos de negociação: a negociação distributiva e a negociação integrativa. Robbins e Judge (2014) afirmam que os dois tipos são distintos em meta, motivação, foco, interesses, compartilhamento de informações e duração do relacionamento.

A negociação distributiva pode ser definida como a negociação que distribui partes de uma quantia fixa. Neste tipo de negociação, para que uma das partes negociantes ganhe mais benefícios, a outra parte tem que perdê-los. Também conhecida por soma zero, este tipo de negociação tem como meta a obtenção da maior quantidade de vantagens possíveis no que envolve a negociação em questão, sendo motivada pela lógica ganhar-perder, com foco em posições e interesses opostos. Tem baixo nível de compartilhamento de informações, pois quanto maior o nível deste, menores são as chances de obtenção de vantagens. Neste tipo de negociação, a duração do relacionamento entre as duas partes é de curto prazo.

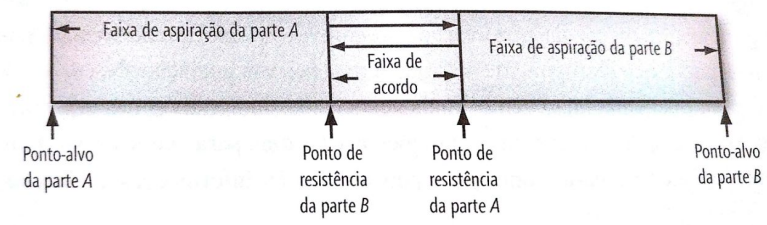

Figura 2. Segmentação da zona de negociação distributiva. Fonte: ROBBINS, S. P; JUDGE, T. A. Fundamentos do Comportamento Organizacional. Pearson, 2014, 496 p.

A figura 2 ilustra a segmentação de zonas de negociação distributiva, onde A e B correspondem aos negociadores. Estes negociadores tem um ponto-alvo, o qual representa o que eles pretendem atingir com aquela negociação. Ambos também tem um ponto de resistência, que define qual seria o resultado mínimo aceitável. A área que se forma entre o ponto alvo e o ponto de resistência é conhecida como faixa de aspiração. Caso não haja nenhuma sobreposição nas faixas de aspiração de A e B, surge uma faixa de acordo, onde ambas as partes encontram seus interesses.

A negociação integrativa, em divergência com a distributiva, tem como motivação o ganho mútuo, onde as partes acreditam que uma ou mais soluções são possíveis para que haja o maior ganho possível para estas. Sendo assim, os objetivos de cada uma das partes negociantes não são mutuamente excludentes, mas ambas as partes obtém seus interesses e anseios. A negociação integrativa tem a meta de expandir os resultados para que as partes fiquem satisfeitas. O foco da integrativa está no entendimento da importância dos interesses dos negociantes, buscando criar interesses congruentes, com alto nível compartilhamento de informações e preocupação com o mantenimento de um relacionamento com duração de longo prazo ${ }^{6} 11$.

Por fim, Robbins e Judge (2014), definem um modelo de processo de negociação. Este modelo é constituído de etapas consecutivas: Preparação e planejamento, Definição de regras básicas, esclarecimento e justificativa, barganha e resolução de problemas e encerramento e implementação.

A primeira etapa, denominada "Preparação e Planejamento", consiste na elucidação de algumas questões antes da negociação. Tais questões são relacionadas à definição da natureza do conflito, seus antecendentes, os envolvidos no conflito e suas respectivas percepções. Nesta etapa também deve ser definido o objetivo do gerente do conflito na negociação.

Na segunda etapa, chamada de "Definição de regras básicas", inicia-se a determinação de procedimentos e diretrizes básicas da negociação. É definido quem fará a negociação, onde ocorrerá, limitação de tempo e de conteúdos em pauta. Nesta etapa, as partes negociantes trocam as propostas iniciais, apresentam interesses, aspirações e objetivos.

"Esclarecimento e justificativa"é designada a terceira etapa do modelo preposto, onde, a partir da apresentação de propostas, interesses, aspirações e objetivos, as partes ampliam, explicam, esclarecem, enfatizam e justificam suas reinvidicações iniciais. Evitar conflitos nesta etapa é fundamental, sendo uma oportunidade de ressaltar a importância das demandas solicitadas e entender os objetivos. Esta etapa pode ser decisiva para partir para uma negociação distributiva ou integrativa. Portanto, é importante apresentar documentações e indicadores que reforcem sua posição.

Em sequência, na quarta etapa, denominada "barganha e resolução de problemas", ocorre um momento essencial no processo de negociação. Neste ponto, as partes vão empenharse para chegar a um acordo, fazendo concessões e requisições conforme seus objetivos.

Por fim, na etapa de "encerramento e implementação", a negociação acaba com a formalização dos termos estabelecidos por ambas partes e de processos para a execução e acompanhamento do que fora negociado. Tal formalização pode ser realizada através de um contrato, assinatura de ata ou simples aperto de mão, simbolizando comprometimento entre os negociadores em respeitar o acordo definido.

A partir dos princípios e concepções apresentadas nesta sessão, definições de conflito, suas consequências organizacionais e delineamentos sobre a resolução de conflitos, é incontestável a importância da gestão de conflitos em qualquer 
tipo de organização, sendo uma competência fundamental para líderes e gerentes, para que possam conduzir as relações inter e intragrupos conforme os objetivos da organização.

Posto isso em evidência, a gestão de conflitos tem como príncipio a negociação, a qual, conforme demonstrado, exige em todas as suas etapas, por parte dos negociantes, além das habilidades tecnicistas, aptidões emocionais de relacionamento intra e interpessoal, como a autoconsciência, autocontrole, automotivação, empatia, habilidades sociais, Gestão de Relacionamentos e entre outras consideradas pilares fundamentais da inteligência emocional.

\section{4) Conceituação de Inteligência Emocional}

Salovey e Mayer (1989; pag.189), os criadores do conceito de inteligência emocional (IE), a definem como "a habilidade de monitorar os sentimentos e emoções de si próprio e dos outros, para discriminar entre eles e usar essa informação para orientar o pensamento e ações. " [Tradução-livre]. Também conhecida por Quociente Emocional ou Quociente de Inteligencia Emocional, a inteligência emocional é apontada por Salovey e Mayer (1989) como uma subarea da inteligência social, a qual foi descrita por Edward Thorndike em 1920.

Os autores conceituaram, na época, três habilidades básicas da inteligencia emocional: A avaliação e expressão das emoções; A Regulação das emoções; e a Utilização das Emoções. Conforme a figura 3, é possivel visualizar ainda subdivisões de aptidões dentro destas três habilidades básicas.

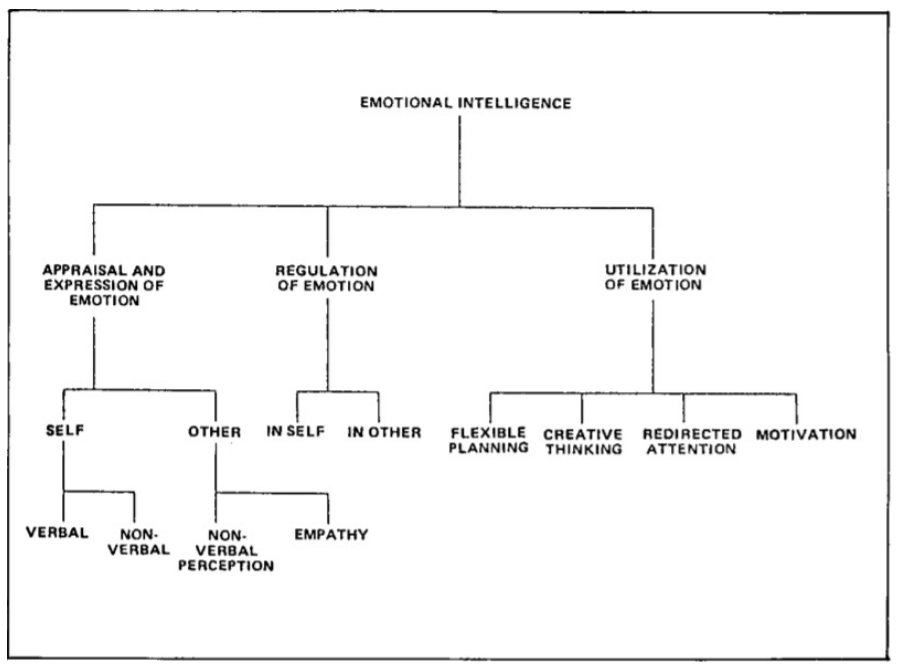

Figura 3. Conceituação de Inteligência Emocional. Fonte: SALOVEY, P; MAYER, J. D. Emotional Intelligence. IMAGINATION, COGNITION AND PERSONALITY, Vol. 9(3) 185-211, 1989-90.

A habilidade de "Avaliação e Expressão das Emoções"é a capacidade de percepção e demonstração das emoções em si de forma verbal e não verbal. Também corresponde à percepção e demonstração das emoções dos outros de forma não verbal. Por fim, conceituam a empatia, que pode ser definida como a capacidade de compreender os sentimentos dos outros, isto é, a facilidade de colocar-se no lugar do outro. Pode-se perceber, neste momento, a importância desta habilidade para um gestor de conflitos em todas as etapas de uma negociação.

A habilidade de "Regulação das Emoções"em si mesmo, é a capacidade de lidar com as emoções e controlar impulsos verbais e não verbais. Esta habilidade também se relaciona com lidar com as emoções dos outros, administrando a manifestação verbal e não verbal de sentimentos e emoções em outrem. Tal habilidade, tanto para si, quanto em relação ao outro evidenciam grande essencialidade na gestão de conflitos, em especial na etapa de barganha e resolução de conflitos, para que uma negociação não leve à conflitos de relacionamento e consequentemente, disfuncionais.

Por fim, Salovey e Mayer (1989) conceituam a habilidade de "Utilização das Emoções", que consiste em mecanismos para acessar e gerar emoções e estas consequentemente, potencializarem humores e comportamentos que desenvolvem a motivação, o pensamento criativo, foco, capacidades de resolução de problemas e adaptação. Claramente, tais habilidades são fundamentais no momento de gerenciar conflitos e promover negociações cada vez mais integrativas e funcionais para uma organização.

Em complemento, a partir do ano de 1995 emerge mundialmente a importância da IE nas organizações, a partir de publicações de Daniel Goleman, que expandem as concepções de Salovey e Mayer. Goleman (2012), fundamenta a IE em 5 domínios principais: Autoconsciência, Autocontrole, Automotivação, Empatia e Gestão de Relacionamentos.

"Autoconsciência"pode ser definida como a capacidade de reconhecer as próprias emoções, com a percepção dos impactos destas em si e nos outros. Esta habilidade é muito importante na gestão de conflitos, para reconhecer quando um conflito começa a ser disfuncional, tornando-se um conflito de relacionamento.

"Autocontrole"pode ser definido como a habilidade de lidar com as emoções. Além de reconhece-las, é ter a capacidade de administrá-las, controlando impulsos e agindo de forma equilibrada. Tal habilidade, somada à autoconsciência pode garantir a prevenção de conflitos de relacionamento, visto que, ao perceber emoções negativas em si, como raiva, irritabilidade, insegurança, medo e aborrecimento manifestando-se durante um conflito ou processo de negocição, pode-se administrar a evolução destas e de possíveis consequências disfuncionais para a organização.

A "Automotivação"é denominada pela junção de otimismo, foco e criatividade, sendo um componente fundamental para avançar, mesmo frente à adversidades e dificuldades. A automotivação é essencial para quando conflitos organizacionais sejam disfuncionais, gerando desentusiasmo, falta de produtividade e falta de cooperação entre membros de uma equipe.

A "Empatia", é a capacidade de perceber os feedbacks verbais e não verbais que são consequências de emoções em outras pessoas, conforme fora supracitado, conseguir compreender o sentimento do outro em uma determinada situação. A empatia gera coesão, unidade e intimidade nos relacionamentos interpessoais, facilitando a resolução de conflitos através de negociações integrativas. A empatia também é essencial para um gestor, para compreender a natureza de um conflito, seus antecendentes, os envolvidos no conflito e suas respectivas percepções e emoções vinculadas.

Por fim, a capacidade de "Gestão de Relacionamentos"pode ser definida como a aptidão de lidar com relações interpessoais e com as emoções dos outros, está intimamente ligada com a 
empatia, pois a partir a percepção das emoções de outrem, a capacidade de gerenciar relacionamentos possibilita agir da forma mais equilibrada possível, estimulando sentimentos positivos e integradores no outro. Pessoas altamente populares, grandes líderes e gestores tem alta capacidade de gestão de relacionamentos interpessoais ${ }^{6}$. Esta habilidade é fundamental na gestão de conflitos e mediação de negociações complexas.

Sendo assim, com o progresso das pesquisas em neurociências, a conceituação a respeito da inteligência se transformou, ampliando as faculdades necessárias para a obtenção do êxito nos mais diferentes contextos, as quais eram só e somente só vinculadas a altos níveis de inteligência racional e tecnicista. Além do supracitado, a Federação Brasileira de Coaching Integral Sistêmico (FEBRACIS) afirma que pesquisas indicam que "nosso sistema nervoso é altamente diversificado e que diferentes áreas do cérebro processam diferentes tipos de informação, e, com isso, podemos treiná-lo para utilizar de forma positiva nossas emoções.".

Nesta perspectiva, a medida que a inteligência racional considera apenas as capacidades lógicas, matemáticas e analíticas, a inteligência emocional agrega aptições relacionadas à autoconsciência, autocontrole, gestão das próprias emoções, empatia, gestão de relacionamentos e automotivação, sendo um fator fundamental no relacionamento intrapessoal, interpessoal, na gestão de conflitos e no processo de negociação.

Segundo Goleman (2012), o Quociente de Inteligência (QI) e a IE não são conceitos excludentes, porém são distintos. Entretanto, afirma que pessoas com altos níveis de inteligência racional tendem a ter menos aptidões emocionais. Assim, conforme apresentado, tais habilidades são fundamentais nas relações organizacionais, a qual é envolta de conflitos e negociações, portanto o desenvolvimento destas competências deve ser enfatizado, a fim de equilibrar aptidões racionais e tecnicistas com as aptidões emocionais, principalmente em uma área cada vez mais essencial e estratégica nas organizações, a Tecnologia da Informação (TI).

5) A Essencialidade da TI nas organizações modernas

Nos últimos anos tem emergido a discussão sobre o papel da TI nas organizações, devido à evolução de um simples setor de suporte administrativo para um indispensável pilar estratégico, transformando produtos, processos e serviços, propiciando grandes alterações no cenário competitivo organizacional ${ }^{14} 15$.

Neste sentido, a TI inclui, em sua definição mais ampla, uma gama multivariada de soluções e que permeiam vários âmbitos de uma organização, senão todos, isto é, sistemas de informação, softwares e hardwares, sistemas de telecomunição, sistemas de automação e robótica, recursos de multimídia, além de fatores humanos, administrativos e organizacionais. Desta forma, Laurindo et. al (2001; pag.161), afirma que "nenhuma aplicação de TI, considerada isoladamente, por mais sofisticada que seja, pode manter uma vantagem competitiva. Esta só pode ser obtida pela capacidade da empresa em explorar a TI de forma contínua.".

Tal afirmação coloca em evidência que a medida que a TI torna-se mais essencial e integrada à estratégia de uma organização, a gestão desta e de todos os fatores envolvidos terá complexidade diretamente proporcional à esta essencialidade. Assim, a partir desta posição estratégica que a TI tem obtido nas organizações, quando relacionada à aspectos humanos e administrativos, por exemplo, na gestão de projetos que envolvam TI, surge uma dependência imediatada do comportamento organizacional na eficácia e a eficiência destas soluções. A partir destas premissas pode-se concluir que quanto maior a importancia estratégica e essencialidade da TI nas organizações, maior será a probabilidade de conflitos, funcionais e/ou disfuncionais que podem envolver este setor e seus profissionais.

6) Gestão de Conflitos em TI: Evidências Empíricas

Tendo em vista a importância estratégica e a essencialidade da TI nas organizações, o que ocasiona inevitável interrelação entre esta e seus profissionais, com a maioria, senão todos os outros setores de uma organização, o surgimento de conflitos é inexorável. Este processo na maioria das vezes ainda é intensificado no desenvolvimento de vários projetos simultaneamente.

Em pesquisa realizada com 25 gerentes e membros de equipes de desenvolvimento de soluções de TI, Moraes e Laurindo (2012) por meio de um survey de natureza exploratória, objetivaram identificar as principais fontes de conflitos em projetos de TI e as respectivas metodologias de resolução de conflitos utilizadas.

Os autores ressaltam que com a padronização crescente na forma de desenvolvimento de soluções de TI, o diferencial nos resultados alcançados são consequência da maneira como é conduzida a gestão de TI e em especial dos projetos de TI. Com isto, afirmam que [...]"a gestão dos conflitos que surjam durante o desenvolvimento de projetos de TI é um aspecto importante para a obtenção de resultados eficazes na área de TI.".

A partir da análise das percepções dos envolvidos, Moraes e Laurindo (2012) perceberam que em situações de conflitos, são priorizadas alternativas que permitam ganhos mútuos para as partes envolvidas, isto é, há preferência para a utilização de técnicas de negociação integrativa na gestão dos conflitos de TI.

Foram analisadas dez fontes de conflitos, sendo elas: Prioridades, Procedimentos administrativos, Questões técnicas, Responsabilidades, Recursos Humanos (Alocação de pessoal), Custos (Orçamento), Programações (Cronograma), Relacionamentos Interpessoais (Confrontos de personalidades), Equipamentos e instalações e Gastos de capital. Dentre estas, foi observado que conflitos de relacionamento interpessoal estão entre os três com maiores índices de ocorrência, precedido somente de conflitos em relação a prioridades e custos.

Neste sentido, pôde-se observar evidências empíricas que há altos índices de conflitos associados ao relacionamento interpessoal dentro das organizações de TI e de organizações com setores de que implantam soluções de TI. Não obstante, conforme supracitado, conflitos de relacionamento, isto é, conflitos que envolvam o relacionamento interpessoal, são na maioria das vezes, disfuncionais, ocasionando muitos fatores negativos para a organização e podendo gerar ainda, conflitos de tarefa e de processos, levando à uma gestão de conflitos ainda mais complexa e multifatorial.

Com isso, emerge a importância do desenvolvimento de aptidões que corroborem para a diminuição de conflitos de 
relacionamento interpessoal em TI e consequentemente nas organizações, porém para que isto ocorra com eficiência e eficácia, faz-se necessário compreender o perfil do profissional de TI, a fim de compreender quais competências profissionais devem ser desenvolvidas.

\section{7) O perfil do profissional de TI sob a ótica das compe-} tências

No Brasil, o setor de TI começou a ganhar mais consistência entre o fim da década de 80 e início da década de $90^{17}$. Atualmente o setor é amplo e heterogêneo, sendo formado na sua maioria por jovens ${ }^{18}$. A grande parte dos profissionais do setor, cerca de $81 \%$, são do sexo masculino, mediante à aproximadamente $19 \%$ do sexo feminino ${ }^{17}$.

Em pesquisa publicada no início desta década, a Associação para Promoção da Excelência do Software Brasileiro (SOFTEX) em parceria com o Comitê Gestor da Internet no Brasil (CGI.br), a Financiadora de Estudos e Projetos (FINEP) e o Instituto Brasileiro de Geografia e Estatística (IBGE) apresentaram dados sobre o mercado e o profissional de TI. Nesta pesquisa, constatou-se que no ano de 2010 o setor de TI era responsável por $82,9 \%$ da força de trabalho da economia da informação, isto é 1.172.829 milhões de trabalhadores, onde a grande maioria possuía registro trabalhista ou previdenciário. Entre os subsetores de atuação estão: A Indústria, com a fabricação de componentes eletrônicos, equipamentos de informática, comunicação e periféricos; $\mathrm{O}$ comércio, que inclui a venda varejista de produtos de TI; e serviços, na sua maioria, relacionados à telecomunicações, atividades dos serviços de TI e prestação de manutenção a equipamentos de informatica e comunicação.

Em vista do cenário supracitado, as competências profissionais exigidas no mercado de TI são bastante diversificadas conforme a aplitude do mercado. São desde de cargos com exigência de nivel Médio/Técnico a cursos de nível superior e especializações. O mercado exige do profissional de TI competências como: Técnico da Web, Técnico em Operações de TI, Técnico de Assistência ao Usuário, Técnico de Redes e sistemas de computadores, Técnico de engenharia de telecomunicações, Técnico em eletrônica, Administração de Sistemas, Análise de Sistemas, Programação e Desenvolvimento de programas e aplicativos, Engenharia da Computação, Engenharia de Telecomunicações, Ciência da Computação, de nível gerencial e de diretoria de serviços de $\mathrm{TI}^{19}$.

Nesta perspectiva, pode-se perceber que a maioria das competências exigidas pelo mercado envolvem habilidades de inteligência racional, que incluem aptidões racionais, analíticas, de desenvolvimento lógico, com amplas e complexas teorias técnicas, relacionadas à comunicação em linguagens computacionais desde a aplicação até o meio físico. A partir disto e tendo em vista a notável quantidade de conflitos organizacionais em TI que envolvem questões de relacionamento interpessoal, os quais na sua maioria são conflitos disfuncionais, faz-se necessário, o desenvolvimento de competências e aptidões relacionadas à inteligência emocional para profissionais de TI, a fim de minimizar os impactos de conflitos disfuncionais dentro das organizações.

\section{B. A importância das aptidões de Inteligência Emocional} na gestão de conflitos em TI

O desenvolvimento de aptidões de inteligência emocional é fundamental para o equilibrio das competências profissionais exigidas pelo mercado. Competências racionais e emocionais não são excludentes, mas devem ser usadas em conjunto para promover a eficiência e eficácia dentro da gestão de projetos dentro de uma organização, em especial na gestão de conflitos. Na área de TI não seria diferente, ainda mais em um setor que tem uma exigência profissional altamente racional, e na maioria das vezes acaba menosprezando a importância das aptidões de inteligência emocional, gerando consequentemente, altos índices de conflitos disfuncionais de relacionamento interpessoal e impactos negativos nos resultados de uma organização.

Assim, o profissional de TI deve buscar o desenvolvimento destas aptidões e competências emocionais como autoconsciência, autocontrole, automotivação, empatia e gestão de relacionamentos. Segundo (Mersino, 2009), o desenvolvimento de aptidões emocionais levam a impactos diretos na gestão, nos seguintes itens:

- Desenvolvimento de relacionamento com stakeholders que apoiam o sucesso de projetos organizacionais;

- Antecipação e contenção de esgotamentos emocionais;

- Gestão de membros difíceis da equipe;

- Negociação e Gestão de conflitos;

- Tomada de decisão;

- Comunicação eficaz;

- Desenvolvimento de um ambiente de trabalho positivo e alta moral da equipe;

- Atração, inspiração e motivação da equipe, criando uma visualização de cenário voltada à objetivos compartilhados no projeto.

Nesta concepção, o desenvolvimento da inteligência emocional vai muito além da gestão de conflitos em TI e pode impactar diretamente os resultados das organizações em diversos aspectos e até na vida pessoal do trabalhador destas, trazendo feedbacks funcionais para a organização e seus objetivos.

\section{CONClusão}

Este trabalho objetivou suscitar uma reflexão, realizada a partir de uma revisão bibliográfica, sobre a relação de importância da aquisição de competências e aptidões emocionais por profissionais de TI para o êxito na gestão de conflitos profissionais nas organizações.

Foi possivel verificar que os conflitos são inerentes às organizações, podendo agregar de forma funcional ou disfuncional aos objetivos das organizações. Conflitos podem ser de tarefa, de relacionamento ou de processo, sendo os de relacionamento na maioriadas vezes disfuncionais, prejudicando os objetivos organizacionais e podendo levar a muitos conflitos de tarefa e de processos, tornando a situação ainda mais complexa e disfuncional.

A gestão de conflitos eficiente tem como princípio a compreenção do processo de negociação e seus tipos, para adequalo às diferentes situações conflituosas. Para negociar com excelência, conclui-se que é necessário seguir um determinado 
processo, o qual em suas fases é imprecidível ter aptidões de inteligência emocional como autoconsciência, autocontrole, empatia e gestão de relacionamentos.

Tendo em vista a crescente essencialidade da TI nas organizações e sua respectiva importância estratégica, envolvendo a maioria, senão todos os contextos e setores de uma organização, a inter-relação da TI com o restante da organização tornase muito intensa, aumentando a probabilidade de conflitos, os quais, conforme apresentado por Moraes e Laurindo (2012), são significativamente ocasionados por questões de relacionamento interpessoal e portanto disfuncionais, provocando insucesso na conquista dos objetivos organizacionais.

Conclui-se, a partir dos fundamentos apresentados de forma empírica neste trabalho, que o desenvolvimento de aptidões de inteligência emocional para o profissional de TI são essenciais na gestão de conflitos organizacionais, podendo ser consideradas competências profissionais indispensáveis para contribuir na conquista dos objetivos organizacionais de forma eficaz e eficiente.

\section{AGRADECIMENTOS}

Agradecemos primeiramente às instituições UNIVEM e IFSP, que oportunizaram a elaboração deste trabalho, utilizado como requisito para conclusão do MBA em Gestão de TI. Em continuidade, somos gratos à todos os envolvidos direta $\mathrm{e}$ indiretamente, em especial à família, aos amigos e colegas de curso.

\section{REFERÊNCIAS}

1 ELIAS, L; DALMAU, M. B. L; BERNARDINI, I. S. Importância da Gestão de Conflitos nas Relações de Trabalho: um estudo de caso na Secretaria de Saúde de Biguaçu/SC. Coleção Gestão da Saúde Pública - Volume 8, 2013. Disponível em: < http : //gsp.cursoscad.ufsc.br/wp/wp content/uploads/2013/03/Artigo $07 . p d f>$

2 McINTYRE, S. E. Como as pessoas gerem o conflito nas organizações: Estratégias individuais negociais. Análise Psicológica, 2007, 2 (XXV): 295-305. Disponível em: $<$ http : //www.scielo.mec.pt/pdf/aps/v25n2/v25n2a09.pdf >

3 MESSERSMITH, J. Managing work-life conflict among information technology workers. Hum. Resour. Manage., 2007, 46: 429-451. doi: $10.1002 / \mathrm{hrm} .20172$

4 GOLEMAN, D. Inteligência Emocional: A teoria revolucionária que redefine o que é ser inteligente. Objetiva, 2012, 384 p.

5 KATZ, R. L.Skills of an effective administrator. Harvard Business Review, n. 52, p. 90-102, Sept./Oct. 1974

6 ROBBINS, S. P; JUDGE, T. A. Fundamentos do Comportamento Organizacional. Pearson, 2014, 496 p.

7 FERREIRA, A. B. H. Mini Aurélio: o dicionário da Língua Portuguesa. 7.ed. rev. e atualizada. Rio de Janeiro: Positivo, 2009.

8 HOUAISS, A; VILLAR, M. S; FRANCO, F. M. M. Houaiss: da Língua Portuguesa. 1.ed. Rio de Janeiro: Objetiva, 2009.

9 JEHN, K. A. A Qualitative Analysis of Conflict Types and Dimensions in Organizational Groups. Administrative Science Quarterly. doi:10.2307/2393737. 1997

10 YANG, J; MOSSHOLDER, K. W. Decoupling task and relationship conflict: the role of intragroup emotional processing. J. Organiz. Behav., 25: 589-605. doi:10.1002/job.258. 2004.
11 LEWICKI, R. J; SAUNDERS, D. M; BARRY, B. Fundamentos de Negociação. 5.ed. New York, The McGraw Hill Education, 2014, 315 p.

12 SALOVEY, P; MAYER, J. D. Emotional Intelligence. IMAGINATION, COGNITION AND PERSONALITY, Vol. 9(3) 185-211, 1989-90.

13 FEDERAÇÃO BRASILEIRA DE COACHING INTEGRAL SISTÊMICO (FEBRACIS). Como ser inteligente emocionalmente pode impactar no seu sucesso?. 2018. Disponível em: $\quad<h t$ tps://www.febracis.com.br/blog/como-ser-inteligenteemocionalmente>.

14 LAURINDO, F. J. B; et,al. O papel da tecnologia da informação (TI) na estratégia das organizações. GESTÃO\&PRODUÇÃO v.8, n.2, p.160-179, ago. 2001. Disponível em: $<$ http://www.scielo.br/pdf/gp/v8n2/v8n2a04>.

15 OLIVEIRA, C. L. C; LAURINDO, F. J. B. Estratégia $e$ a internet: estudos de casos em empresas brasileiras. Production, dx.doi.org/10.1590/0103-6513.060212. 2013. disponível em: $<$ http://www.scielo.br/pdf/prod/2015nahead/0103-6513-prod-01036513060212.pdf>.

16 MORAES, R. O; LAURINDO, F. J. B. Conflitos em Projetos de Tecnologia da Informação - evidências empíricas encontradas de um survey. Espacios. Vol. 33 (4). 2012. Pág. 9. disponível em: <http://www.revistaespacios.com/a12v33n04/12330409.html>

17 CASTRO, B. Gênero e trabalho na tecnologia da informação: um perfil dos profissionais do setor no Brasil. XV Congresso Brasileiro de Sociologia, 2011.

18 IEGER, E. M; BRIDI, M. A. Profissionais de TI: perfil e o desafio da qualificação permanente. ABET, v. 13, n. 2, 2014. Disponível em: $<$ <ttp://www.periodicos.ufpb.br/ojs/index.php/abet/article/view/25676>.

19 ASSOCIAÇÃO PARA PROMOÇÃO DA EXCELÊNCIA DO SOFTWARE BRASILEIRO (SOFTEX). Cadernos temáticos do observatório: economia da informação e internet. Ed. Publit, 2013. 145 p. Disponível em: <https://www.softex.br/wp-content/uploads/2013/07/Cadernostematicos-do-observatorio-economia-da-informacao-e-internet1.pdf>.

20 MERSINO, A. Inteligência emocional para gerenciamento de projetos. 1.ed. São Paulo, M.Books, 2009. 247 p. 